\title{
Results of treatment in amblyopia associated with unilateral high myopia without strabismus
}

\author{
DHAN KRISHNA SEN \\ From the Department of Ophthalmology, Maulana Azad Medical College and associated Irwin Hospital and \\ Guru Nanak Eye Centre, New Delhi, India
}

SUMMARY Fifty-five patients with amblyopia in unilateral high myopia without strabismus were treated. Thirty-two $(58 \%)$ had a visual improvement by two lines or more on the Snellen chart and $17(31 \%)$ attained a final visual acuity of $6 / 12$ or better. In patients with pretreatment corrected vision of $6 / 60$ or better in the amblyopic eye treatment consisted of full-time occlusion of the good eye, in some cases supplemented by the after-image method of pleoptic exercises in the amblyopic eye. Overall improvement of vision in this group was $72.7 \%$. Occlusion of the good eye combined with pleoptic exercises in the amblyopic eye had no advantage over simple occlusion of the good eye. In patients with pretreatment corrected vision worse than $6 / 60$ in the amblyopic eye occlusion of the amblyopic eye was done and the after-image method of pleoptic exercises was instituted. Improvement of vision in this group was $36 \cdot 3 \%$. The study showed that it is worth the trouble to treat this disorder even after the age of 14 years and stresses the utility of pleoptic therapy in older patients with severe amblyopia.

Few reports show that patients with amblyopia in unilateral high myopia can be treated successfully. ${ }^{1-4}$ However, many of the patients observed in those studies had associated strabismus, and it is difficult to determine whether the amblyopia was caused by the strabismus, the anisometropia, or both. ${ }^{56}$ Moreover, the cases so far treated and reported belonged to the younger age group. In India many children with unilateral high myopia and amblyopia report at a more advanced age, as there are no proper health screening facilities in most of the schools.

Our purpose was to study the results obtained by treating these older patients and to compare the results with those obtained in the younger age group, and also to stress the value of pleoptic therapy in older children with unilateral high myopia and severe amblyopia.

\section{Patients and methods}

The patients were referred to the amblyopia clinic of Irwin Hospital and Guru Nanak Eye Centre by fellow ophthalmologists. None of them had any amblyopia therapy before reporting to us. We did a thorough

Correspondence to Dr Dhan Krishna Sen, V/4, MAM College Campus, Kotla Road, New Delhi-110002, India. general ophthalmological examination, including ophthalmoscopy. Vision was tested by means of Snellen chart. A complete orthoptic examination was done, including cover test, red glass test, Bagolini striated glass test, and bifoveal correspondence test of Cüppers. In many patients bifoveal fixation was also tested by having the patient superimpose Haidinger's brushes on a real object. Ocular fixation was studied by using projectoscope with the Linksz star graticule.

Only cases of unilateral high myopia with central fixation and without strabismus were included, and a full cycloplegic refraction was done in all of them. They were fully corrected with glasses. Contact lenses were given to patients with higher degree of myopia or who did not tolerate the prescribed glasses. The patients were asked to continue wearing them fulltime until no further improvement in vision occurred.

In 55 patients the visual acuity did not improve to $6 / 12$ or better even after full-time wearing of glasses for six weeks or more. They were divided into the following groups for the treatment of amblyopia: (1) Of the 33 patients with corrected visual acuity $6 / 60$ or better 19 had only full-time occlusion of the good eye, and in 14 patients full-time occlusion of the good eye was supplemented with Cüppers' after-image method of pleoptic exercises in the amblyopic eye to see if the combined therapy was more helpful in increasing the 
percentage of success or expediting visual recovery. Cüppers' after-image method of pleoptic exercises by means of a projectoscope fitted with an autodisc has been described by Priestley et al. ${ }^{2}$ Treatment with it was given one-half to one hour a day for five days a week. Patients in these two subgroups were matched for age, degree of myopia, and depth of amblyopia to ensure comparability of results. (2) Twenty-two patients with corrected vision worse than $6 / 60$ had full-time occlusion of the amblyopic eye (as they did not tolerate the occlusion of the good eye which brought their schooling and outdoor activities to a complete halt) and Cüppers' after-image method of pleoptic exercises as described by Priestley et al. ${ }^{2}$ When the vision in this group of patients improved sufficiently with this treatment, the occlusion was transferred to the good eye and pleoptic therapy was discontinued. We encouraged all the patients wearing the patch on the good eye to do home exercises involving fine visual tasks to provide enough stimulation to the fovea of the amblyopic eye. They were evaluated for progress once a week.

The cases were counted as failures when there was no improvement at all or only one line improvement after appropriate therapy for a period of four months. In successful cases, once the best possible visual acuity was obtained, full-time occlusion was replaced by part-time occlusion, the scheduling of which was planned for each individual patient. Orthoptic exercises were prescribed for all successful patients to improve binocular functions. Finally, we directed the patients to continue patching of the good eye one day a week, preferably on Sundays, for three hours as a precaution against return of amblyopia. The visual acuity and refraction were rechecked at six months' intervals. The period of follow-up was from four to six years.

Table 1 Relation of degree of myopia to age at presentation

\begin{tabular}{lrrrr}
\hline $\begin{array}{l}\text { Age in } \\
\text { years }\end{array}$ & \multicolumn{2}{l}{$\begin{array}{l}\text { Dioptres of myopia in spherical } \\
\text { equivalents }\end{array}$} & $\begin{array}{l}\text { Total no. of } \\
\text { patients }\end{array}$ \\
\cline { 2 - 5 } & $5-10$ & $11-15$ & $16-21$ & \\
\hline $7-14$ & $18(50 \cdot 0 \%)$ & $11(30 \cdot 5 \%)$ & $7(19 \cdot 5 \%)$ & $36(100 \cdot 0 \%)$ \\
$15-22$ & $9(47 \cdot 4 \%)$ & $6(31 \cdot 6 \%)$ & $4(21 \cdot 0 \%)$ & $19(100 \cdot 0 \%)$ \\
$\begin{array}{l}\text { Total no. of } \\
\text { patients }\end{array}$ & $27(49 \cdot 0 \%)$ & $17(31 \cdot 0 \%)$ & $11(20 \cdot 0 \%)$ & $55(100 \cdot 0 \%)$ \\
\hline
\end{tabular}

For statistical analysis of the results non-parametric distribution-free tests such as Wilcoxon's rank sum test and Jonckheere's test ${ }^{7}$ were sometimes preferred to the conventional tests of significance to avoid misleading conclusions due to possible deviations of the data from normality.

\section{Results}

\section{CLINICAL DATA}

The age of the patients ranged from 7 to 22 years (mean 12.8 years). Thirty-six $(65.4 \%)$ were aged 7 to 14 years and $19(34.6 \%)$ were 15 to 22 years. Twentyfive $(45.4 \%)$ were boys and $30(54.6 \%)$ were girls. The right eye had high myopia in $35(63.6 \%)$ patients. The amblyopic eye had a mean myopia of 11.4 dioptres in spherical equivalents (range, -5 to -21 dioptres in spherical equivalents). A refractive error ranging between -3.50 dioptres and +2.00 dioptres in spherical equivalents was present in the fellow eye. In all the patients a difference of more than -5 dioptres existed between the spherical equivalents of the two eyes. Vision before treatment was $6 / 60$ or better in $33(60 \%)$ patients and worse than $6 / 60$ in 22 patients $(40 \%)$.

The degrees of myopia as related to the age at presentation are given in Table 1 . We found no statistically significant association between the two $\left(\chi^{2}=\right.$ 0.04 for 2 DF, $p>0.95)$. There was, however, a statistically significant relationship $\left(\chi^{2}=37.60\right.$ for 3 DF, $\mathrm{p}<0.001)$ between the age at presentation and the depth of amblyopia (Table 2); the higher the age the greater was the depth of amblyopia. We also analysed the correlation of the degree of myopia with the depth of amblyopia and found that, though there was a suggestion of higher degrees of myopia being associated with severe degrees of amblyopia (Table $3)$, it failed to attain statistical significance $\left(\chi^{2}=5 \cdot 23\right.$ for $2 \mathrm{DF}, 0 \cdot 05<\mathrm{p}<0 \cdot 10)$.

\section{RESPONSE TO TREATMENT}

We regarded the amblyopia therapy as successful when there was a visual improvement of at least two lines on the Snellen chart. Thirty-two of $55(58 \%)$ patients met this criterion, and 17 of $55(31 \%)$ attained a final visual acuity of $6 / 12$ or better. We have given the number of patients improved separately in

Table 2 Relation of corrected pretreatment visual acuity to age at presentation

\begin{tabular}{|c|c|c|c|c|c|c|}
\hline \multirow{2}{*}{$\begin{array}{l}\text { Age in } \\
\text { years }\end{array}$} & \multicolumn{5}{|c|}{ Pretreatment visual acuity } & \multirow{2}{*}{$\begin{array}{l}\text { Total no. of } \\
\text { patients }\end{array}$} \\
\hline & $<6 / 60$ & $6 / 60$ & $6 / 36$ & $6 / 24$ & $6 / 18$ & \\
\hline $7-14$ & $12(33 \cdot 3 \%)$ & $8(22 \cdot 2 \%)$ & $6(16 \cdot 7 \%)$ & $8(22 \cdot 2 \%)$ & $2(5 \cdot 6 \%)$ & $36(100 \cdot 0 \%)$ \\
\hline $15-22$ & $10(52 \cdot 7 \%)$ & $4(21.0 \%)$ & $3(15 \cdot 8 \%)$ & $2(10 \cdot 5 \%)$ & $0(0 \cdot 0 \%)$ & $19(100 \cdot 0 \%)$ \\
\hline Total no. of patients & $22(40 \cdot 0 \%)$ & $12(21 \cdot 8 \%)$ & $9(16.4 \%)$ & $10(18 \cdot 1 \%)$ & $2(3 \cdot 6 \%)$ & $55(100 \cdot 0 \%)$ \\
\hline
\end{tabular}


Table 3 Relation of corrected pretreatment visual acuity to degree of myopia

\begin{tabular}{|c|c|c|c|c|c|}
\hline \multirow{2}{*}{$\begin{array}{l}\text { Dioptres of myopia in } \\
\text { spherical equivalents }\end{array}$} & \multicolumn{4}{|c|}{ Pretreatment visual acuity } & \multirow{2}{*}{$\begin{array}{l}\text { Total no. of } \\
\text { patients }\end{array}$} \\
\hline & $<6 / 60$ & $6 / 60$ & $6 / 36$ & $6 / 24-6 / 18$ & \\
\hline $5-10$ & $7(26 \cdot() \%)$ & $6(22 \cdot 2 \%)$ & $5(18 \cdot 5 \%)$ & $9(33.3 \%)$ & $27(100 \cdot 0 \%)$ \\
\hline $11-15$ & $8(47 \cdot 1 \%)$ & $3(17 \cdot 6 \%)$ & $4(23 \cdot 5 \%)$ & $2(11 \cdot 8 \%)$ & $17(100 \cdot 0 \%)$ \\
\hline $16-21$ & $7(63.6 \%)$ & $3(27 \cdot 3 \%)$ & $0(0 \cdot 0 \%)$ & $1(9.1 \%)$ & $11(100 \cdot 0 \%)$ \\
\hline Total no. of paticnts & $22(40 \cdot(0 \%)$ & $12(21 \cdot 8 \%)$ & $9(16.4 \%)$ & $12(21.8 \%)$ & $55(100 \cdot(0 \%)$ \\
\hline
\end{tabular}

Table 4 Results of treatment related to degree of myopia and corrected pretreatment visual acuity

\begin{tabular}{|c|c|c|c|c|c|c|}
\hline \multirow{2}{*}{$\begin{array}{l}\text { Dioptres of myopia } \\
\text { in spherical } \\
\text { equivalents }\end{array}$} & \multicolumn{5}{|c|}{ Pretreatment visual acuity } & \multirow{2}{*}{$\begin{array}{l}\text { Total no. of } \\
\text { patients }\end{array}$} \\
\hline & $<6 / 60$ & $6 / 60$ & $6 / 36$ & $6 / 24$ & $6 / 18$ & \\
\hline \multicolumn{7}{|c|}{ Patients aged 7 to 14 years } \\
\hline $5-10$ & $2(1) / 4^{*}$ & $3(1) / 4$ & $2(2) / 3$ & $4(4) / 5$ & $2(2) / 2$ & $13(10) / 18$ \\
\hline $11-15$ & $2(0) / 4$ & $1(0) / 2$ & $2(1) / 3$ & $2(2) / 2$ & $0(0) / 0$ & $7(3) / 11$ \\
\hline $16-21$ & $1(0) / 4$ & $1(0) / 2$ & $0(0) / 0$ & $1(1) / 1$ & $0(0) / 0$ & $3(1) / 7$ \\
\hline \multicolumn{7}{|c|}{ Patients aged 15 to 22 years } \\
\hline $5-10$ & $2(0) / 3$ & $1(0) / 2$ & $2(2) / 2$ & $1(1) / 2$ & $0(0) / 0$ & $6(3) / 9$ \\
\hline $11-15$ & $1(0) / 4$ & $1(0) / 1$ & $0(0) / 1$ & $0(0) / 0$ & $0(0) / 0$ & $2(0) / 6$ \\
\hline $16-21$ & $0(0) / 3$ & $1(0) / 1$ & $0(0) / 0$ & $0(0) / 0$ & $0(0) / 0$ & $1(0) / 4$ \\
\hline Total no. of patients & $8(1) / 22$ & $8(1) / 12$ & $6(5) / 9$ & $8(8) / 10$ & $2(2) / 2$ & $32(17) / 55$ \\
\hline
\end{tabular}

${ }^{*}$ Numerator gives the total number of patients improved. Numerator in parentheses gives the number of patients improving to $6 / 12$ or better. Denominator gives the total number of patients in each subgroup.

relation to age groups 7 to 14 years and 15 to 22 years (Table 4). It was observed that patients aged 7 to 14 years improved their vision more often $(63.8 \%, 23$ of 36 ) than those aged 15 to 22 years $(47 \cdot 3 \%, 9$ of 19$)$. However, the difference in the improvement rate between the two groups was not statistically significant $\left(\chi^{2}=1.40\right.$ for $\left.1 \mathrm{DF}, \mathrm{p}>0 \cdot 20\right)$.

The average number of lines of improvement in different age groups in patients with pretreatment visual acuity $6 / 60$ or better by two methods of treat-

Table 5 Average visual improvement in lines on Snellen chart in different subgroups of patients

\begin{tabular}{|c|c|c|}
\hline & \multirow{2}{*}{\multicolumn{2}{|c|}{$\begin{array}{l}\text { Average visual improve- } \\
\text { ment in lines with therapy } \\
\text { Age in years }\end{array}$}} \\
\hline & & \\
\hline . & $7-14$ & $15-22$ \\
\hline \multicolumn{3}{|l|}{ Pretreatment vision } \\
\hline $\begin{array}{l}\text { 6/60 or better ( } 33 \text { patients): } \\
\text { occlusion of good eye ( } 19 \text { patients) } \\
\text { occlusion of good eye and pleoptic }\end{array}$ & $1 \cdot 8$ & $1 \cdot 8$ \\
\hline $\begin{array}{l}\text { therapy in amblyopic eye ( } 14 \text { patients) } \\
\text { Worse than } 6 / 60 \text { ( } 22 \text { patients) } \\
\text { occlusion of amblyopic eye and pleoptic } \\
\text { therapy }\end{array}$ & $2 \cdot 1$ & $2 \cdot 2$ \\
\hline \multicolumn{3}{|l|}{ Dioptres of myopia in spherical equivalents } \\
\hline $\begin{array}{r}5-10 \\
11-15 \\
16-21\end{array}$ & $\begin{array}{l}1 \cdot 9 \\
2 \cdot 0 \\
1 \cdot 0\end{array}$ & $\begin{array}{l}2 \cdot 1 \\
1 \cdot 0 \\
0 \cdot 8\end{array}$ \\
\hline
\end{tabular}

ment are given in Table 5. Wilcoxon's rank sum test showed that there was no significant difference in the results obtained by simple occlusion of the good eye and occlusion of the good eye supplemented with pleoptic exercises in the amblyopic eye either in the age group 7 to 14 years $(p=0.51)$ or in the age group 15 to 22 years $(p=0 \cdot 30)$. The mean period of treatment for visual recovery in the patients with simple occlusion of the good eye was seven months and that in the patients with occlusion of the good eye combined with pleoptic exercises in the amblyopic eye was six months. A single tailed Wilcoxon's rank sum test showed that there was no significant difference either in the age group 7 to 14 years $(p=0.09)$ or in the age group 15 to 22 years $(p>0.90)$ in the time taken for visual recovery by the two methods of treatment.

We recorded visual improvement in $36.3 \%$ ( 8 of 22) patients with corrected vision worse than $6 / 60$. The average number of lines of improvement in different age groups in this category of patients are given in Table 5 . Here also there was no significant difference $(p=0.67)$ in the improvement rate between the two age groups 7 to 14 years and 15 to 22 years. The mean period of treatment for visual recovery in these patients was nine months (range 6 to 14 months). We have also given the results of treatment related to degree of myopia in Table 5. It was found that in the younger age group the rate of improvement was not influenced by the degree of myopia $(p=0 \cdot 12)$, whereas 
Table 6 Results of treatment in relation to degree of astigmatism

\begin{tabular}{lccccccc}
\hline $\begin{array}{l}\text { Dioptres of } \\
\text { astigmatism }\end{array}$ & \multicolumn{9}{l}{ Lines of improvement } & & \begin{tabular}{l} 
Total no. \\
of \\
\cline { 2 - 7 }
\end{tabular} & $0-1$ & 2 & 3 & 4 & 5 & patients \\
\hline 0 & 9 & 5 & 3 & 2 & 1 & 20 \\
1 & 1 & 2 & 3 & 1 & 0 & 7 \\
2 & 6 & 4 & 4 & 3 & 0 & 17 \\
3 & 4 & 1 & 1 & 0 & 0 & 6 \\
4 & 2 & 0 & 2 & 1 & 0 & 5 \\
Total no. & 22 & 12 & 13 & 7 & 1 & 55 \\
of patients & 22 & & & & & & \\
\hline
\end{tabular}

in the older age group the rate of improvement was significantly higher in those with lesser degrees of myopia $(p=0.048)$.

We analysed the correlation of the degree of astigmatism with the rate of improvement (Table 6) and found no association (Jonckheere's test giving $p=0.90$ ). Stereopsis as tested with the Titmus fly and the Worth 4-dot test before and after therapy is given in Table 7. It may be noted that a considerable number of patients had some form of binocular vision before therapy, and the percentage improved considerably after therapy.

\section{Discussion}

In this series high myopia was found in the right eye in most $(63.6 \%)$ of the patients. This agrees with the finding of Rosenthal and Von Noorden ${ }^{3}$ and Cambiaggi $^{8}$ but is at variance with that of Priestley $e t$ $a l .,{ }^{2}$ who found a preponderance of high myopia in the left eye. Rosenthal and Von Noorden ${ }^{3}$ found that the severity of amblyopia corresponded to the amount of myopia, and in patients with myopia 15 dioptres or more the corrected vision was always less than $6 / 60$ (20/200). However, we failed to find any such correlation and observed that all the categories of myopia had both poor and relatively good levels of corrected visual acuity.

Treatment of amblyopia in unilateral high myopia used to be neglected owing to the belief that the chances of visual recovery in these patients were remote. Bangerter ${ }^{1}$ was the first to stimulate interest in the subject by treating 16 patients with pleoptic therapy and reporting a $25 \%$ success (visual acuity $6 / 12$ or better). Jonkers," however, stated that any therapy in such cases would fail. Priestley et al. ${ }^{2}$ treated 21 patients with pleoptics and obtained a visual gain of $6 / 12(20 / 40)$ or better in $15 \%$ cases. Rosenthal and Von Noorden ${ }^{3}$ treated 29 patients with simple occlusion of the good eye and achieved success in $76 \%$ of them and an improvement of $6 / 12$ $(20 / 40)$ or better in $24 \%$ cases. Pollard and Manley ${ }^{4}$ treated 40 patients also with the simple occlusion of the good eye and obtained success in $75 \%$ cases, with visual acuity improving to $6 / 12(20 / 40)$ or better in $55 \%$ cases. However, none of the previous workers considered patients with amblyopia in unilateral high myopia over the age of 14 years for treatment. Pollard and Manley ${ }^{4}$ observed that, while younger patients responded better to therapy, improvement might be seen up to 14 years of age on rare occasions. Results obtained in the present study show that $50 \%$ of the patients reporting even after the age of 14 years are expected to improve with treatment if they are properly motivated. Moreover, it is interesting that some of our patients above 14 years of age showed much greater improvement than some of the children below 14 years did.

Occlusion of the good eye was supplemented with pleoptic exercises in the amblyopic eye in some patients with pretreatment corrected vision $6 / 60$ or better to see if the combined therapy enhanced the percentage of success and/or shortened the period of visual recovery. However, the study shows that the combined therapy has no advantage over simple occlusion of the good eye.

Rosenthal and Von Noorden ${ }^{3}$ and Pollard and Manley ${ }^{4}$ showed that simple occlusion of the good eye was as effective as occlusion of the amblyopic eye and pleoptic therapy practised earlier by Bangerter ${ }^{1}$ and Priestley $e t a l .{ }^{2}$ As a result a feeling gained ground that these patients need not be subjected to the rigours of pleoptic therapy. However, in older children with severe amblyopia (vision worse than 6/60) who do not tolerate the occlusion of the good eye, occlusion of the amblyopic eye and pleoptic therapy is the treatment of choice.

Prognosis as to visual recovery was found to be related to the degree of myopia only in the older age

Table 7 State of binocular function

\begin{tabular}{|c|c|c|c|c|c|}
\hline \multirow{2}{*}{$\begin{array}{l}\text { Age in } \\
\text { years }\end{array}$} & \multirow{2}{*}{$\begin{array}{l}\text { No. of } \\
\text { patients }\end{array}$} & \multicolumn{2}{|c|}{ Stereopsis (Titmus fly) } & \multicolumn{2}{|c|}{ Peripheral fusion (Worth 4-dot test) } \\
\hline & & $\begin{array}{l}\text { Before } \\
\text { therapy }\end{array}$ & $\begin{array}{l}\text { After } \\
\text { therapy }\end{array}$ & $\begin{array}{l}\text { Before } \\
\text { therapy }\end{array}$ & $\begin{array}{l}\text { After } \\
\text { therapy }\end{array}$ \\
\hline $7-14$ & $36(100 \cdot(0 \%)$ & $8(22 \cdot 2 \%)$ & $18(50 \cdot 0 \%)$ & $12(33 \cdot 3 \%)$ & $25(70 \cdot 0 \%)$ \\
\hline $15-22$ & $19(100.0 \%)$ & $3(16 \cdot 0 \%)$ & $7(37.0 \%)$ & $6(31 \cdot 6 \%)$ & $13(68.4 \%)$ \\
\hline Total no. of patients & $55(10(0) \cdot(0 \%)$ & $11(20.0 \%)$ & $25(45 \cdot 5 \%)$ & $18(33 \cdot 0 \%)$ & $38(70 \cdot 0 \%)$ \\
\hline
\end{tabular}


group of 15 to 22 years, where the greater the degree of myopia the worse was the prognosis. However, Rosenthal and Von Noorden ${ }^{3}$ found the prognosis to be worse in young patients in whom the myopia was greater than 15 dioptres.

It is desirable to monitor these patients closely for signs of regression. The improvement in visual acuity dropped off in three out of 40 patients of Pollard and Manley. ${ }^{4}$ and in approximately one-half the cases of Rosenthal and Von Noorden ${ }^{3}$ after the occlusion was discontinued. Although in such an eventuality occlusion of the good eye rapidly re-establishes the previously gained good vision, one should not take chances. The patient should be advised to continue occlusion of the good eye once a week for a few hours, which he can easily do at home on Sundays without curtailing any social or outdoor activities. It may be mentioned that with this regimen none of our patients showed any sign of regression within the follow-up period of four to six years.

I thank Mr G. P. Mathur, statistician, New Delhi Tuberculosis Centre, New Delhi, for the statistical calculations and evaluation of the data. I also thank Mr Baljit Singh, senior orthoptist, and Mrs Neclam Upmanyus, junior orthoptist, in the department for tcchnical assistance.

\section{References}

1 Bangerter A. Amblyopia behandlung. 2nd ed. Basel: Karger, 1955: 90.

2 Priestley BS, Hermann JS, Bloom M. Amblyopia secondary to unilateral high myopia: results of pleoptic therapy. $A m J O p h$ thalmol 1963; 56: 926-32.

3 Rosenthal AR, Von Noorden GK. Clinical findings and therapy in unilateral high myopia associated with amblyopia. Am J Ophthalmol 1971; 71: 873-9.

4 Pollard ZF, Manley D. Long-term results in the treatment of unilateral high myopia with amblyopia. Am J Ophthalmol 1974; 78: 397-9.

5 Helveston EM. Rclationship between the degrec of anisometropia and the depth of amblyopia. Am J Ophthalmol 1966; 62: 757-9.

6 Von Noorden GK. Burian-Von Noorden's binocular vision and ocular motility. 2nd cd. St Louis: Mosby, 1980: 222.

7 Leach C. Introduction to statistics. A nonparametric approach for the social sciences. New York: Wilcy, 1979: 49-76, 169-82.

8 Cambiaggi A. Researches on predilection of monocular myopia for the right eye. Ophthalmologica 1960; 140: 259-66.

9 Jonkers GH. The indications for pleoptic and orthoptic treatment Klin Monatsbl Augenheilkd 1960; 137: 145-55. 